\title{
A Study of Role of Prophylactic Magnesium Sulphate in Severe Preeclampsia in Preventing Eclampsia
}

\author{
Dr. T. Shobha ${ }^{1}$, Dr. P. Rajani ${ }^{2}$ \\ ${ }^{1}$ Associate Professor Modern Government Maternity Hospital, Petlaburz, Department of Obstetrics and Gynaecology,Osmania Medical \\ College, Hyderabad - Telangana
}

${ }^{2}$ Post Graduate, Gandhi Hospital, Department of Obstetrics and Gynaecology, Gandhi Medical College, Hyderabad - Telangana

\begin{abstract}
Aim of the Study: The aim of present study is to determine the role of Prophylactic Magnesium Sulphate in severe pre eclampsia in preventing eclampsia. The goal is to prevent seizures and its complications on mother and fetus by early detection and intervention before onset of imminent signs and symptoms of eclampsia. Materials and Methods: The study was undertaken from September 2010 to September 2012 in department of obstetrics and gynaecology at Gandhi hospital, Secunderabad which is a teaching hospital and a tertiary referral centre as well. The study is a cross sectional interventional type of study. Results: The complications of severe preeclampsia like eclampsia, pulmonary oedema and renal failure occurred more in group not given magnesium sulphate (2\%,1\%,1\% given vs $11 \%, 3 \%, 4 \%$ not given) respectively and incidence of abruption and DIC in is almost similar in both groups.(4\% and 1\% Vs 3\%and 1\%). And with no maternal mortality in both groups. The magnesium sulphate administered group showed more associated side effects when compared to other group. The symptoms of toxicity like loss of deep tendon reflexes, oliguria and other side effects like nausea, head ache, flushing and vomiting had higher incidence in magnesium sulphate administered group. Conclusion: The study has revealed that women with severe preeclampsia, when given prophylactic magnesium sulphate before onset of imminent signs, had less chances of landing up in eclampsia and its complications, compared to the one not given. Hence administration of prophylactic magnesium sulphate to prevent eclampsia, in all cases of severe preeclampsia, even before the onset of imminent signs is justified.
\end{abstract}

Keywords: pre eclampsia, eclampsia, Magnesium Sulphate, seizures

\section{Introduction}

Hypertensive disorders complicate 5 to $10 \%$ of the pregnancies, among which preeclampsia and eclampsia are important causes of maternal morbidity and mortality ${ }^{1}$ Preeclampsia complicates 5 to $7 \%$ of all the pregnancies out of which $3.3 \%$ develop severe preeclampsia ${ }^{2}$ and less than $1 \%$ land into eclampsia ${ }^{3}$ which is the second most common cause of maternal and perinatal morbidity in under privileged population ${ }^{4}$. In eclampsia maternal mortality is $10 \%$ and fetal mortality is 20 to $30 \%$. In developed countries eclampsia is rare, affecting around 1 in 2000 deliveries ${ }^{6}$ while in developing countries estimates varies from 1 in 100 to 1 in $1700^{7,8}$. World wide an estimated 600,000 women die each year of pregnancy related causes ${ }^{9}$, with $99 \%$ of these deaths occurring in developing countries. Preeclampsia and eclampsia account for about 50,000 maternal deaths a year ${ }^{10}$. Hence early identification and interventions are mandatory to overcome these complications of preeclampsia.

For decades anticonvulsant drugs have been given to women with preeclampsia in the belief that they reduce the risk of seizures and so improve the outcome ${ }^{11}$.In 1998, a systematic review $^{12}$ of anticonvulsant for women with preeclampsia identified 4 trials comparing anticonvulsant with no anticonvulsant or placebo. These concluded Magnesium sulphate to be the most promising choice for prophylaxis in severe pre eclampsia, in preventing eclampsia.

Magnesium sulphate was used as Cathartic, Hydrogogue in local Fomentation for 200 years. First reports on its efficacy were published in the year 1905 and 1906. In 1927 Alton and Lincoln used Magnesium sulphate intrathecally, since then it was used in the treatment of eclampsia. Many methods of administration and dosage schedules evolved since then. Later Lazard, Dorsette, Eastman, Pritchard, Chesley, Tapper, Zuspan, Hell and Flowers each one of them contributed information regarding the dosage, body distribution and excretion of the drug.

Though the drug was administered with reasonable obstetric judgement high recurrence of convulsions occurred due to inadequate dosage of Magnesium sulphate which led to introduction of various regimens of administration of Magnesium sulphate to attain a therapeutic serum concentrations.

In 1965 Flowers developed a dosage schedule on the basis of body weight and urine concentration. Pritchard, Chesley, Dieckman, Tapper combined intravenous dose with intramuscular dose to attain desired plasma concentrations and believed that intramuscular route is as effective as intravenous route and safer in preventing sudden respiratory arrest.

Despite such early suggestions of its potential, the choice of Magnesium sulphate for seizure prophylaxis has continued to vary enormously. In United States for example Magnesium sulphate is the drug of choice for women with eclampsia or pre eclampsia, while in United Kingdom it was used by only $2 \%$ of obstetricians in 1922. Over years the use of magnesium sulphate for preeclampsia was deemed more a religious conviction than a scientifically established treatment. 


\section{International Journal of Science and Research (IJSR) \\ ISSN (Online): 2319-7064}

Index Copernicus Value (2013): 6.14 | Impact Factor (2015): 6.391

Sibai advocated the use of Magnesium sulphate even in cases of moderate preeclampsia while Redman mentioned that anticonvulsants were only indicated if eclampsia occurred. However the collaborative Magpie trail has been instrumental in introducing Magnesium sulphate as a prophylactic agent in the prevention of eclampsia. In spite of such evidence Magnesium sulphate as a prophylactic agent is still under used. Some centres restrict its use only after the onset of imminent signs .In India few similar North Indian studies are available, one of which suggest it to be a good prophylactic agent and the other shows no much difference in occurrence of seizures with its usage. There are no similar South Indian studies carried out, though many studies regarding Magnesium sulphate as an anticonvulsant in eclampsia has been studied.

The present study is cross sectional interventional study conducted to determine the role or efficacy of magnesium sulphate as a prophylactic agent in all cases of severe preeclampsia in preventing eclampsia .In many institutes, routine protocol is to administer magnesium sulphate after the onset of imminent signs or convulsions. In the present study magnesium sulphate has been initiated before the onset of imminent signs. The Study has been conducted after approval from ethical committee.

\section{Materials and Methods}

The study was undertaken from September 2010 to September 2012 in department of obstetrics and gynaecology at Gandhi hospital, Secunderabad which is a teaching hospital and a tertiary referral centre as well. The study is a cross sectional interventional type of study.

\section{Inclusion criteria}

All antenatal women both primi and multi gravid satisfying the diagnostic criteria of severe pre eclampsia, were included. These women were either in labour or those in whom termination has been decided and free of any imminent signs of eclampsia. As appearance of imminent sign is a surest indication for administration of magnesium sulphate in our institution, women with imminent signs requiring magnesium sulphate were excluded from study.

\section{Criteria for Severe Preeclampsia:}

1) Severe hypertension, BP $>160 / 110 \mathrm{~mm}$ of $\mathrm{Hg}$ or more.

2) Proteinuria $>5 \mathrm{gm} / 24 \mathrm{hr}$ or $2+$ or more in random urine samples.

3) Elevated serum creatinine levels $>0.8 \mathrm{mg} / \mathrm{dl}$.

4) Pulmonary oedema.

5) Oliguria $<500 \mathrm{ml} / 24 \mathrm{hrs}$.

6) Micro angiopathic haemolysis.

7) Thrombocytopenia with platelets $<1 \mathrm{lakh} / \mathrm{cu} \mathrm{mm3.}$

8) Elevated ALT and AST.> 40 IU/L.

\section{Exclusion criteria}

Following women have been excluded

- Cases of severe preeclampsia with symptoms of imminent eclampsia have been excluded.

- Cases of chronic hypertension with no superimposed pre eclampsia.

- Hypertension due to other causes.

- Women with epilepsy.
- Women with medical disorders like conductive cardiac failure, myasthenia gravis or other neuromuscular disorders.

\section{Method}

100 women with severe pre eclampsia either in labour or in whom decision for termination has been taken were selected and history noted according to proforma and followed up till discharge. These women who received magnesium sulphate were compared with100 women who were similarly followed and did not receive magnesium sulphate. The new born of both groups were observed till discharge.

In present study Pritchard's regimen was used, to administer magnesium sulphate as it is widely accepted and has been proven to be more effective and attain a good therapeutic serum values compared to other regimens and it's simpler to administer in a set up like ours.

Pritchard's regimen is administration of a loading dose of 4 gms of $20 \%$ magnesium sulphate intravenously into accessible peripheral vein generally cubital vein over 15-20 minutes followed by $10 \mathrm{gms}$ of $50 \%$ magnesium sulphate deep intramuscular one half in each buttock .

Followed by maintenance dose of magnesium sulphate $5 \mathrm{gms}$ of $50 \%$ solution of magnesium sulphate every fourth hourly for 24 hours from the start of first dose under strict monitoring for toxicity.

Magnesium sulphate toxicity was monitored by clinical signs of loss of tendon reflexes, drowsiness, oliguria and respiratory distress. Serum magnesium levels were not monitored due to poor affordability of women in study. Magnesium sulphate was discontinued once toxic signs appeared. And calcium gluconate antidote was kept available.

In group not given magnesium sulphate with severe pre eclampsia if women had convulsions or developed symptoms of imminent eclampsia like headache, epigastric pain, blurred vision the trail was stopped and was given magnesium sulphate and monitored.

\section{Observation}

Table 1: Age Distribution of Total Cases

\begin{tabular}{|c|c|c|c|}
\hline AGE & Mgso4 -given & Mgso4-notgiven & Total \\
\hline$<21 \mathrm{yrs}$ & $52(52 \%)$ & $23(23 \%)$ & 75 \\
\hline $21-25 \mathrm{yrs}$ & $46(46 \%)$ & $65(65 \%)$ & 111 \\
\hline$>25 \mathrm{yrs}$ & $2(2 \%)$ & $12(12 \%)$ & 14 \\
\hline Total & $100(100 \%)$ & $100(100 \%)$ & 200 \\
\hline
\end{tabular}

Both the groups, magnesium given and not given, included mostly the women belonging to age group less than 25 years. $(98 \%$ and $88 \%)$ respectively. 


\section{International Journal of Science and Research (IJSR) \\ ISSN (Online): 2319-7064 \\ Index Copernicus Value (2013): 6.14 | Impact Factor (2015): 6.391}

Table 2: Case Distribution among Primigravida and Multigravida

\begin{tabular}{|c|c|c|c|}
\hline & Mgso4-given & Mgso4-not given & Total \\
\hline Primi gravida & $69(69 \%)$ & $66(66 \%)$ & 135 \\
\hline Gravida 2 & $25(25 \%)$ & $17(17 \%)$ & 42 \\
\hline Gravida 3 and more & $6(6 \%)$ & $17(17 \%)$ & 23 \\
\hline Total & $100(100 \%)$ & $100(100 \%)$ & 200 \\
\hline
\end{tabular}

There were more women who belonged to primi gravida in both the groups. (69\%given and $66 \%$ not given) compared to multi gravida (31\% and $34 \%$ ) in given and not given groups respectively.

Table 3: Case Distribution According to Gestational Age at Delivery

\begin{tabular}{|c|c|c|c|}
\hline & Mgso4-given & Mgso4-not given & Total \\
\hline Term gestation & $48(48 \%)$ & $60(60 \%)$ & 108 \\
\hline $33-36$ weeks & $37(37 \%)$ & $38(38 \%)$ & 75 \\
\hline 28-32 weeks & $15(15 \%)$ & $2(2 \%)$ & 17 \\
\hline Total & $100(100 \%)$ & $100(100 \%)$ & 200 \\
\hline
\end{tabular}

The study included most of the cases belonging to term gestation. (48\% and 60\%) in given and not given groups respectively.

Women with gestational age less than 32 weeks were significantly very low (2\%) in group not given magnesium sulphate when compared to $(15 \%)$ in magnesium sulphate group as a whole, women with preterm pregnancy were more in magnesium sulphate administered group.

Table 4: Comparision of Onset of Labour in Vaginal Deliveries

\begin{tabular}{|c|c|c|}
\hline & Mgso4-given & Mgso4-not given \\
\hline Spontaneous onset of labour & $8(16 \%)$ & $7(13.46 \%)$ \\
\hline Induced labour & $42(84 \%)$ & $45(86.53 \%)$ \\
\hline Total & $50(100 \%)$ & $52(100 \%)$ \\
\hline
\end{tabular}

Among the vaginal deliveries women in both groups mostly required induction (84\% in given and $86.53 \%$ in not given) and very few cases landed up in spontaneous labour. (16\% and $13.46 \%$ ) in given and not given groups respectively.

Table 5: Comparison of Mode of Delivery

\begin{tabular}{|c|l|l|l|}
\hline & Mgso4-given & Mgso4-not given & TOTAL \\
\hline SPVD & $35(35 \%)$ & $48(48 \%)$ & 83 \\
\hline INS & $15(15 \%)$ & $4(4 \%)$ & 19 \\
\hline CS & $50(50 \%)$ & $48(48 \%)$ & 98 \\
\hline TOTAL & $100(100 \%)$ & $100(100 \%)$ & 200 \\
\hline
\end{tabular}

The women who landed up in caesarean section were almost equal in both groups ( $(50 \%$ in given and $48 \%$ in the group not given).

Among the vaginal deliveries the instrumental delivery was significantly more in magnesium sulphate administered group ( $15 \%$ vs $4 \%$ ) this difference of $\mathbf{1 1 \%}$ is statistically significant.
Table 6: Comparison of Indications for Cesarean Section

\begin{tabular}{|c|c|c|c|}
\hline & Mgso4-given & Mgso4-not given & Total \\
\hline Previous section & $15(30 \%)$ & $13(27.08 \%)$ & 28 \\
\hline Fetal distress & $19(38 \%)$ & $19(39.58 \%)$ & 38 \\
\hline Dystocia & $13(26 \%)$ & $13(27.08 \%)$ & 26 \\
\hline UHTN & $3(6 \%)$ & $3(6.2 \%)$ & 6 \\
\hline Total & $50(100 \%)$ & $48(100 \%)$ & 98 \\
\hline
\end{tabular}

The indications for caesarean section were almost similar in both groups the commonest cause being fetal distress $(38 \%$ in given and $39.58 \%$ in not given) and previous caesarean section (30\% in given and $27.08 \%$ in not given) followed by dystocia $(26 \%$ and $27.08 \%)$ respectively in given and not given groups.

Table 7: Maternal Out Come With Respect to Complications of Severe Pre Eclampsia

\begin{tabular}{|l|l|l|l|}
\hline & Mgso4 -given & Mgso4-not given & Total \\
\hline Eclampsia & $2(2 \%)$ & $11(11 \%)$ & 13 \\
\hline Abruption & $4(4 \%)$ & $3(3 \%)$ & 7 \\
\hline Renal failure & $1(1 \%)$ & $3(3 \%)$ & 4 \\
\hline Pulmonary oedema & $1(1 \%)$ & $4(4 \%)$ & 5 \\
\hline DIC & $1(9 \%)$ & $1(1 \%)$ & 2 \\
\hline HELLP/MM & - & - & - \\
\hline
\end{tabular}

The complications of severe preeclampsia like eclampsia, pulmonary oedema and renal failure occurred more in group not given magnesium sulphate $(2 \%, 1 \%, 1 \%$ given vs $11 \%$, $3 \%, 4 \%$ not given) respectively and incidence of abruption and DIC in is almost similar in both groups. $(4 \%$ and $1 \%$ Vs $3 \%$ and $1 \%$ ). And with no maternal mortality in both groups.

Table 8: Comparison of Incidence of Eclampsia

\begin{tabular}{|c|c|c|c|}
\hline & Mgso4 -given & Mgso4 -not given & Total \\
\hline Eclampsia & $2(2 \%)$ & $11(1 \mathrm{SS} 1 \%)$ & 13 \\
\hline Eclampsia free & $98(98 \%)$ & $89(89 \%)$ & 187 \\
\hline Total & $100(100 \%)$ & $100(100 \%)$ & 200 \\
\hline
\end{tabular}

Eclampsia is a grave complication of severe preeclampsia occurred more in the group not given magnesium sulphate compared to group given magnesium sulphate (11\% vs $2 \%$ ). This difference of $9 \%$ is statistically significant with Chi square value $=4.4103$ and $P$ value $<0.05$ which is statistically significant, indicating that intervention with magnesium sulphate has better maternal out come when given to women with severe pre eclampsia.

Table 9: Comparison of Side Effects With Magnesium Sulphate

\begin{tabular}{|c|c|c|c|}
\hline & Mgso4 -given & Mgso4-not given & Total \\
\hline LDTR & 22 & - & 22 \\
\hline Oliguria & 24 & 12 & 36 \\
\hline RD & 2 & 4 & 6 \\
\hline PPH & - & - & - \\
\hline $\begin{array}{c}\text { Other complaints } \\
\text { N/V/F }\end{array}$ & 20 & 6 & 26 \\
\hline
\end{tabular}

The magnesium sulphate administered group showed more associated side effects when compared to other group. The symptoms of toxicity like loss of deep tendon reflexes, oliguria and other side effects like nausea, head ache, flushing and vomiting had higher incidence in magnesium sulphate administered group.

\section{Volume 5 Issue 6, June 2016 www.ijsr.net}

Licensed Under Creative Commons Attribution CC BY 


\section{International Journal of Science and Research (IJSR) \\ ISSN (Online): 2319-7064}

Index Copernicus Value (2013): 6.14 | Impact Factor (2015): 6.391

Table 10: Comparison of Neonatal Out Come in Both Gruops

\begin{tabular}{|c|c|c|c|}
\hline Apgar score at birth & Mgso4 -given & Mgso4-not given & Total \\
\hline $7-10$ & $40(40 \%)$ & $46(46 \%)$ & 86 \\
\hline $3-6$ & $32(32 \%)$ & $10(10 \%)$ & 42 \\
\hline$<3$ & $24(24 \%)$ & $40(40 \%)$ & 64 \\
\hline Still birth & $4(4 \%)$ & $4(4 \%)$ & 8 \\
\hline Total & $100(100 \%)$ & $100(100 \%)$ & 200 \\
\hline
\end{tabular}

Nearly $40 \%-50 \%$ of new borns from both groups had good Apgar of 7-10 (40\% given and 46\% not given) respectively and women with 3-6 Apgar were more in magnesium sulphate administered group (32\% vs $10 \%$ ) respectively in given and not given groups and less than 3 Apgar of ( $24 \%$ given vs $40 \%$ not given) with slight higher incidence in group not given magnesium sulphate and still births had similar incidence in both groups.(4\% in each group).

Table 11: Distribution of Nicu Admissions According to Gestational Age At Delivery

\begin{tabular}{|c|c|c|}
\hline Gestational age of newborn & Mgso4-given & Mgso4 not given \\
\hline 32weeks and less & $16(45.71 \%)$ & $29(5.55 \%)$ \\
\hline More than 32 weeks & $19(54.28 \%)$ & $34(94.44 \%)$ \\
\hline Total & $35(100 \%)$ & $36(100 \%)$ \\
\hline
\end{tabular}

Both groups had equal NICU admissions .The magnesium sulphate given group had more of 32 and less gestational age new born NICU admissions compared to other group ( $45.71 \%$ given vs $5.55 \%$ not given). where as the group not given magnesium sulphate had more $>32$ weeks gestational age new born admissions.(94.44\% in not given vs $54.28 \%$ in given ).

Table 12: Out come of total NICU Admissions $->32 \mathrm{WKS}$ and 32 and Less Gestatinal Age Newborn

\begin{tabular}{|c|c|c|}
\hline & Mgso4 -given & Mgso4 - not given \\
\hline Discharged & $30(85.71 \%)$ & $31(86.11 \%)$ \\
\hline Dead & $5(15.625 \%)$ & $5(13.8 \%)$ \\
\hline TOTAL & $35(100 \%)$ & $36(100 \%)$ \\
\hline
\end{tabular}

The outcome of total NICU admissions was almost comparable in both groups with almost equal percentages of deaths and discharges which included both new born of $(>32$ weeks and $<32$ weeks).

Table 13: NICU out come in newborn more than 32 weeks

\begin{tabular}{|l|l|l|}
\hline & Mgso4-given & Mgso4-not given \\
\hline Discharged & $19(100 \%)$ & $31(91.18 \%)$ \\
\hline Dead & 0 & $3(8.82 \%)$ \\
\hline Total & $19(100 \%)$ & $34(100 \%)$ \\
\hline
\end{tabular}

When new born of more than 32 weeks, the salvageable neonates admitted to NICU were considered, the outcome was better in group given magnesium sulphate with no deaths and there were about $8.82 \%$ of deaths in group not given magnesium sulphate.

\section{Discussion}

Eclampsia remains a complex and partially understood disease and its prophylaxis is the area of greatest controversy. Although magnesium sulphate is a proven anticonvulsant in eclampsia, its role in prophylaxis is less certain.

The present study is conducted at Gandhi Hospital, Secunderabad from Sep 2010 to 2012, and 200 severe preeclamptic women were studied.

The present study included more number of booked cases compared to unbooked, as pre eclampsia being high risk pregnancy; women had regular antenatal visits and were referred early in pregnancy. And major part of booked cases formed a part of group not given magnesium sulphate, as their blood pressures were under control with good antenatal visits. And un booked cases referred directly with high uncontrollable blood pressures constituted major part of magnesium sulphate administered group.

The women in the present study were mostly of age group less than 25years (98\% in given and $88 \%$ in not given) compared to above 25 years age group. (2\% given and $12 \%$ not given) respectively. where as in a study conducted by Omu et al in the year2007 Women in the age group of 3140years $(n=208,46.3 \%)$ were more likely to have severe preeclampsia compared with younger and older counterparts (OR $=1.55,95 \%$ CI 1.40-1.71, p! 0.001), especially in their first pregnancy, and ours being a developing country due to early marriages we had more number of young pregnant women (less than 25 years) with severe preeclampsia.

Primigravida formed the major part of study in both groups. And preeclampsia is known to occur more commonly in primigravida. As concluded in study by Omu et al, in 2007 Primigravidity had an important association with preeclampsia (OR $=2.20,95 \%$ CI 2.01-2.41, p! 0.001). And in Altman, Magpie trail 2004 number of primi in both groups (2604 (52\%) and 2591 (51\%) were also more compared to multi gravida (217 (4\%) $203(4 \%))$.

The study included both term and preterm pregnancies, as women with severe preeclampsia required early termination of pregnancy. The term and preterm pregnancies were $(48 \%$ and $60 \%$ vs $52 \%$ and $40 \%$ ) in group given magnesium sulphate and not given respectively. This is comparable to studies conducted by the Magpie trail 2002(<34 weeks 112 (18\%) 135 (19\%)) vs. ( > _34 weeks 519 (81\%) $556(80 \%)$ (And also Sohini Bhattacharya study 2010(40\%and 36\% vs $24 \%$ and $16 \%$ ) which also included both term and preterm pregnancies.

Most of the women among vaginal deliveries required induction in both the groups. As pre eclampsia being a high risk pregnancy, most of the women were terminated before onset of spontaneous labour. (91.3\% in given and $88.8 \%$ in not given, required induction vs $8.6 \%$ in given and $11.11 \%$ in not given set into spontaneous labour) respectively in both groups.

Administration of Magnesium sulphate did not affect the outcome of labour like rate of Cesarean section. This conforms to the previous studies. ${ }^{\mathbf{9 2 9 3}}$ While a study by Hall DR, Odendaal HJ, Smith $\mathbf{M}$ Is the prophylactic administration of magnesium sulphate in women with preeclampsia indicated prior to labour? In BJOG 2000 


\section{International Journal of Science and Research (IJSR) \\ ISSN (Online): 2319-7064 \\ Index Copernicus Value (2013): 6.14 | Impact Factor (2015): 6.391}

Jul;107(7):903-908. Reports a high rate of Cesarean section $(68.5 \%)$ done mostly for fetal distress $(38.6 \%)$. we had a Cesarean delivery rate of $50 \%$ in the group receiving magnesium sulphate. Indications being mostly fetal distress (19\%), followed by previous cesarean section (17\%) and dystocia (13\%) and very few with uncontrolled blood pressure $(3 \%)$. Results were similar in group not given magnesium sulphate. Similar to study by Sohini Bhattacharya in 2010 of $50 \%$ of cesarean section rate in group receiving magnesium sulphate mostly done in view of uncontrolled hypertension $42.8 \%$.

Instrumental vaginal delivery rate was higher in magnesium sulphate group with $15 \%$ compared to other group $4 \%$ with a difference of $11 \%$ which is significant statistically indicating that magnesium sulphate has got a tocolytic effect on uterine activity which led to instrumental delivery. This is similar to results obtained in study by Sohini Bhattacharya with more instrumental deliveries in group given magnesium sulphate (20\% vs $4.2 \%)$.

In present study we had a much higher incidence of eclampsia in the severely preeclamptic mothers not receiving magnesium sulphate than the group receiving it $(11 \%$ versus $2 \%$ ). The difference of $\mathbf{9 \%}$ has been calculated to be statistically significant with a $\mathbf{p}$ value of less than 0.05 . This is comparable with the four large randomized trials discussed by Sibai BM showing a lower rate of eclampsia in those assigned to magnesium sulphate $(0.6 \%$ versus $2.0 \%)$. Thus the number of women needed to treat or prevent one case of eclampsia is 71. Follow up data from Magpie Trial, 2004 shows that there were significantly fewer eclamptic convulsions among women allocated magnesium sulphate than among those allocated placebo $(40,0.8 \%$, vs $96,1.9 \%$; i.e., 11 fewer women with eclampsia per 1000 women, $95 \%$ CI 7-16 women; $\mathrm{p}<0.0001$ with $58 \%$ lower risk of eclampsia in the group made to receive magnesium sulphate. While in study conducted by Omu et al only 2(0.4\%) women had eclamptic seizures while on magnesium sulphate therapy. The present study also confirms the Cochrane review of 6 clinical trials involving 11,444 women showing that magnesium sulphate more than halved the risk of eclampsia and maternal death. In study by Sohini Bhattacharya the incidence of convulsions was low in group given magnesium sulphate (4 (8\%) vs12 (25\%).

In Magpie study there were no clear differences between the groups in any measure of maternal morbidity or mortality. Renal failure, liver failure, and coagulopathy are closely related to preeclampsia, with no difference $(117,2.3 \%$, vs $136,2.7 \%$ ) as in trail. The only clear difference in outcome related to pregnancy, labour, or delivery was a lower risk of placental abruption in the magnesium sulphate group than in the placebo group $(90,2 \cdot 0 \%$, vs $141,3 \cdot 2 \%$; i.e., 12 fewer women with an abruption per 1000 women, 99\% CI3-21). This figure represents a $27 \%$ lower relative risk of abruption (99\% CI 11-55; ) In present study, the incidence of other complications of severe preeclampsia like HELLP,DIC(1\% in both the groups,) and abruption (4\% vs 3\%), had almost equal incidence indicating prophylactic magnesium sulphate has no significant effect in controlling these complication of severe pre eclampsia .
Renal failure and pulmonary oedema, which also are the complications of severe pre eclampsia occurred less in group given magnesium sulphate compared to group not given (3\% vs $1 \%$ ) and (4\% vs $1 \%$ ) respectively, indicating role of magnesium sulphate in preventing these complications. However this difference of $2 \%$ and $3 \%$ which is statistically insignificant may be related, as a complication of eclampsia in women not given magnesium sulphate. The role of magnesium sulphate in preventing these complications of severe pre eclampsia needs to be studied more.

In study by Altman 2004 the Magpie trail a quarter of women allocated magnesium sulphate had unwanted sideeffects, compared with 5\% allocated placebo. Although very few of these side-effects were life threatening, most of them were unpleasant and many women experienced multiple side-effects. The present study also had higher incidence of toxic side effects of magnesium sulphate like loss of deep tendon reflexes (20\%), oliguria (24\%) and other side effects like vomiting, flushing sensation $(20 \%)$ in group given magnesium sulphate.

Maternal respiratory depression has been a serious concern in many studies which occurred more commonly in magnesium sulphate, administered women. But in present study slightly higher rate was observed in those who were not administered magnesium sulphate.(4\% vs $2 \%$ ). where as in Altman, Magpie study respiratory distress a lethal complication of magnesium sulphate toxicity was more common in magnesium sulphate given group ( $0.9 \%$ vs $0.5 \%)$ compared to placebo group. This higher incidence of respiratory distress in present study in magnesium sulphate administered group can be explained as complication secondary to eclampsia as these four were the women who had eclampsia followed by respiratory distress secondary to pulmonary oedema.

Although PPH has been reported to be associated with prophylactic magnesium sulphate use in study by Whitlin AG, Friedman SA, Sibai BM The effect of magnesium sulphate therapy on the duration of labour in women with mild preeclampsia at term: a randomized, double-blind, placebo-controlled trial. AmJ Obstet Gynecol. 1997 Mar; 176(3):623-627.the present study had no patient with PPH in both groups. Though study by Sohini Bhattacharya 2010 showed a higher incidence of PPH in group not given magnesium sulphate. ( $4 \%$ vs 0 )

Once magnesium sulphate crosses the placental barrier, there has been concern about its safety for the neonates. Sibai BM states that prophylactic magnesium sulphate has no significant benefit in perinatal outcome when it is given to pregnant women. There are many confounding factors that contribute to adverse neonatal outcome, and therefore make the evaluation of the neonatal outcome after magnesium sulphate therapy difficult. The confounding factors in Omu et al study such as primigravidity (52\%), preterm delivery (56 \%and 53\%) in preeclamptic and eclamptic women, respectively, and intrauterine growth restriction among $30.2 \%$ of the women contributed to adverse neonatal out come. In the Magpie study, more than 53\% of the babies were born underweight (less than $2.5 \mathrm{~kg}$ ) which is another confounding factor. 


\section{International Journal of Science and Research (IJSR) \\ ISSN (Online): 2319-7064 \\ Index Copernicus Value (2013): 6.14 | Impact Factor (2015): 6.391}

Riaz et al. evaluated the effects of maternal magnesium sulphate treatment on newborn babies delivered at 34 weeks of gestation whose mothers received a minimum of 12 hours of intravenous magnesium sulphate, and beyond the immediate post delivery period, there were no additional complications in this cohort, attributable to prenatal magnesium sulphate exposure.

In the present study, overall neonatal outcome was better in group given magnesium sulphate as regards the APGAR scores, NICU admission however there were many confounding factors like pre term delivery, IUGR babies, and low birth weight to assign the effect directly to magnesium sulphate. The group given magnesium sulphate had more number of new borns of less than 32 weeks of age who were admitted to NICU $(42.42 \%$ vs $5.55 \%$ s) and group not given magnesium sulphate had more of new born of gestational age more than 32 weeks. $(94.44 \%$ vs $57.55 \%)$. When new born of more than 32 weeks alone were considered, the death rate was comparatively low in magnesium sulphate administered group (0 vs $8.8 \%$ ) which is statistically significant. However, these deaths occurred remote from the time of exposure to magnesium sulphate. Hence cannot be directly attributed to be the effect of magnesium sulphate.

The Magpie Trial showed no substantitive harmful effects on babies born to mothers on prophylactic magnesium sulphate in the short term.

\section{Summary}

The present study has been conducted at Gandhi Hospital, Secunderabad from September 2010 to September 2012. The study included more of booked cases compared to unbooked. In booked cases most of them belonged to group to whom magnesium sulphate was not given (70\% not given vs $59 \%$ given) and while in unbooked cases most of them were in group who received magnesium indicating poor control of blood pressure in unbooked cases .

There were more women who belonged to primi gravida in both the groups. (69\% given and $66 \%$ not given) compared to multi gravida (31\% and $34 \%$ ) in given and not given groups respectively ( $41 \%$ given vs $30 \%$ not given). This confirms the high incidence of pre eclampsia in primigravida.

Both the groups, magnesium given and not given, included mostly the women belonging to age group less than 25 years that is (98\% and 88\%) respectively, establishing the fact that pre eclampsia more common in young women.

The study included most of the cases belonging to term gestation. (48\% and 60\%) in given and not given groups respectively. Women with gestational age less than 32 weeks were significantly very low $(2 \%)$ in group not given magnesium sulphate when compared to (15\%) in magnesium sulphate group as a whole, women with preterm pregnancy were more in magnesium sulphate administered group. The inclusion of more of preterm pregnancies represents the fact that termination of pregnancy is definitive treatment of pre eclampsia.
Among the vaginal deliveries women in both groups mostly required induction ( $84 \%$ in given and $86.53 \%$ in not given) and very few cases landed up in spontaneous labour. (16\% and $13.46 \%$ ) in given and not given groups respectively. The women who landed up in caesarean section were almost equal in both groups $((50 \%$ in given and $48 \%$ in the group not given).

Among the vaginal deliveries the instrumental delivery was significantly more in magnesium sulphate given group. sAmong the vaginal deliveries the instrumental delivery was significantly more in magnesium sulphate administered group ( $15 \%$ vs $4 \%$ ) this difference of $\mathbf{1 1 \%}$ is statistically significant, representing the tocolytic effect of magnesium sulphate.

The indications for caesarean section were almost similar in both groups the commonest cause being fetal distress $(38 \%$ in given and $39.58 \%$ in not given) and previous caesarean section $(30 \%$ in given and $27.08 \%$ in not given) followed by dystocia (26\% and $27.08 \%)$ respectively in given and not given groups.

The complications of severe preeclampsia like eclampsia, pulmonary oedema and renal failure occurred more in group not given magnesium sulphate $(2 \%, 1 \%, 1 \%$ given vs $11 \%$, $3 \%, 4 \%$ not given) respectively and incidence of abruption and DIC in is almost similar in both groups. $(4 \%$ and $1 \% \mathrm{Vs}$ $3 \%$ and $1 \%$ ). And with no maternal mortality in both groups. This represents the positive outcome of intervention with magnesium sulphate.

Eclampsia is a grave complication of severe preeclampsia occurred more in the group not given magnesium sulphate compared to group given magnesium sulphate (11\% vs $2 \%$ ). This difference of $9 \%$ is statistically significant with Chi square value $=4.4103$ and $P$ value $<0.05$ which is statistically significant, indicating that intervention with magnesium sulphate has better maternal out come when given to women with severe pre eclampsia.

The magnesium sulphate administered group showed more associated side effects when compared to other group. The symptoms of toxicity like loss of deep tendon reflexes, oliguria and other side effects like nausea, head ache, flushing and vomiting had higher incidence in magnesium sulphate administered group.

Nearly $40 \%-50 \%$ of new borns from both groups had good Apgar of 7-10 (40\% given and 46\% not given) respectively and women with 3-6 Apgar were more in magnesium sulphate administered group (32\% vs 10\%) respectively in given and not given groups and less than 3 Apgar of $(24 \%$ given vs $40 \%$ not given) with slight higher incidence in group not given magnesium sulphate and still births had similar incidence in both groups.(4\% in each group).

Both groups had equal NICU admissions .The magnesium sulphate given group had more of 32 and less gestational age new born NICU admissions compared to other group ( $45.71 \%$ given vs $5.55 \%$ not given). where as the group not given magnesium sulphate had more $>32$ weeks gestational 


\section{International Journal of Science and Research (IJSR) \\ ISSN (Online): 2319-7064}

Index Copernicus Value (2013): 6.14 | Impact Factor (2015): 6.391

age new born admissions.(94.44\% in not given vs $57.55 \%$ in given ).

When new born of more than 32 weeks, the salvageable neonates admitted to NICU were considered, the outcome was better in group given magnesium sulphate with no deaths and there was about $8.82 \%$ of death in group not given magnesium sulphate and this is pointing towards role of magnesium sulphate in improving fetal survival.

\section{Conclusion}

The study has revealed that women with severe preeclampsia, when given prophylactic magnesium sulphate before onset of imminent signs, had less chances of landing up in eclampsia and its complications, compared to the one not given. Hence administration of prophylactic magnesium sulphate to prevent eclampsia, in all cases of severe preeclampsia, even before the onset of imminent signs is justified.

Other associated complications like renal failure and pulmonary oedema also had lesser incidence in study group which needs further studies to justify its association with prophylactic magnesium sulphate.

However higher incidence of magnesium sulphate associated side effects, calls for better regimens based on body mass and ethnicity, which would attain therapeutic levels with lower doses and lesser side effects and this needs further studies considering serum magnesium levels and its relation to toxic symptoms, which could not be done in the present study.

Perinatal outcome had positive association with administration of magnesium sulphate in the present study, when new born of more than 32 weeks were considered. To establish this association further studies are required taking into consideration all the confounding factors like IUGR, preterm babies and other fetal insults which are related to severe preeclampsia rather than magnesium sulphate effect.

\section{References}

[1] Ascarelli MH, Vanessia RN, Warren LM et al. Individually determined postpartum magnesium sulphate therapy with clinical parameters to safely and cost-effectively shorten treatment for preeclampsia. Am J Obstet Gynecol 1998; 179:952-56.

[2] WitlinS AG, Sibai BM. Magnesium sulphate therapy in preeclampsia-eclampsia. Obstet Gynecol 1998; 92(5): 883-89.

[3] Hauth H. Hypertension disorders of pregnancy Cunningham FG, Gant NF, Leveno KG et al. Obstetrics William's $21^{\text {st }}$ edition chapter 24 , Ma c Graw Hill 2001.pp 2001.pp. 568-609.

[4] Suman S, Shivanjali M, Patil A, et al. Low dose magnesium sulphate therapy for eclampsia and imminent eclampsia: Regime tailored for Indian women. J Obstet Gynecol Ind 2003;53 (6):546-50.

[5] Duley L, Johnson R. Magnesium sulphate for preeclampsia and eclampsia: the evidence so far. Br J Obstet Gynaecol 1994;101:565-67.
[6] Douglas K, Redman C. Eclampsia in the United Kingdom. BMJ 1994;309: 1395-400.

[7] Crowther CA. Eclampsia at Harare maternity hospital. S Afr Med J1985; 68: 927-29.

[8] Bergstrom S, Povey G, Songane F, Ching C. Seasonal incidence of eclampsia, its relationship to meteorological data in Mozambique.J Perinat Med 1992; 20: 153-58.

[9] WHO, UNICEF. Revised 1990 estimates of maternal mortality: WHO/FRH/MSM/96.11. Geneva: WHO, 1996.

[10]Duley L. Maternal mortality associated with hypertensive disorders of pregnancy in Africa, Asia, Latin America and the Caribbean.Br J Obstet Gynaecol 1992; 99: 547-53.

[11] Roberts JM. Magnesium for preeclampsia and eclampsia. $N$ Engl J Med 1995; 333: 250-51.

[12] Duley L, Gülmezoglu AM, Henderson-Smart D. Anticonvulsants for women with preeclampsia (Cochrane Review). In: The Cochrane Library, Issue 1. Oxford: Update Software, 2002.

[13] Management of hypertension in pregnancy: Executive summary. Australasian Society for the Study of Hypertension in Pregnancy. Med J Aust. 1993 May 17;158(10):700-2.

[14] Brown MA, Lindheimer MD, de Swiet M, Van Assche A, Moutquin JM.: The classification and diagnosis of the hypertensive disorders of pregnancy: statement from the International Society for the Study of Hypertension in Pregnancy (ISSHP). Hypertensive Pregnancy. 2001; 20(1): IX-XIV.

[15] National High Blood Pressure Education Programme: Working Group Report on High Blood Pressure in Pregnancy. Am J Obstet Gynecol 183:51 ,2000.

[16]ACOG American College of Obstetricians and Gynecologists: Diagnosis and management of preeclampsia and eclampsia. Practice Bulletin No. 33, January 2002.

[17] Kahn HA, Sempos CT. Statistical methods in epidemiology.New York, NY: Oxford University Press, 1989:137-48.

[18] 18 . Sibai BM . Diagnosis and Management of gestational hypertension and preeclampsia. Obstet Gynecol2003; 102:1891-92.

[19] Sibai BM, Ewell M, Levine RJ, et al: Risk factors associated with preeclampsia in healthy nulliparous women. Am J Obstet Gynecol 177:1003,1997.

[20] Spencer J, Polavarapu S, Tlmms D et al: Regional and monthly variation in rates of preeclampsia at delivery among U.S.births.Abstract no 294Presented at 29th Annual Meeting of the Society for Maternal Fetal Medicine, January 26-31, 2009.

[21] Eduard Gratac, Pere-Joan Torres,Vicenc Cararach, Lloren Quinto, Pedro L.AJonso and Albert Fortuny Does the use of contraception reduce the risk of pregnancy-induced hypertension? Human Reproduction vol 11 no 10 pp 2138-2141, 1996.

[22] Helena Salonen Ros, Sven Cnattingius, and Loren Lipworth: Comparison of Risk Factors for Preeclampsia and Gestational Hypertension in a Population-based Cohort Study, American Journal of Epidemiology Vol. 147, No. 11. 


\section{International Journal of Science and Research (IJSR) \\ ISSN (Online): 2319-7064}

Index Copernicus Value (2013): 6.14 | Impact Factor (2015): 6.391

[23] Knuist M, Bonsel GJ, Zondervan HA, Treffers PE: Intensification of fetal and maternal surveillance in pregnant women with hypertensive disorders. Int $\mathbf{J}$ Gynecol Obstet 1998; 61:127.

[24] Pallab Rudra, Sonela Basak, Dilip Patil and M Y Latoov: Recent Advances In Management Of Preeclampsia; BJMP 2011; 4(3):a433

[25] Chesley, L. C., Annitto, J. D., and Cosgrove, R. A. (1968): The familial factor in toxemia of pregnancy. Obstetrics and Gynaecology, 32, 303-311.

[26] Chesley, L. C., Cosgrove, R. A., and Annitto, J. E. (1962): Pregnancies in the sisters and daughters of eclamptic women. Obstetrics and Gynaecology, 20, 3946.

[27] Sonia Hernandez Diaz, Sengwee Toh,Sven Cnattingius: Risk of preeclampsia in first and subsequent pregnancies: prospective cohort study. BMJ 2009; 338:bmj.b2255

[28] Anne Cathrine Staff, Ralf Dechend,Robert Pijnenborg: Acute Atherosis and Vascular Remodeling in Preeclampsia-Novel Aspects for Atherosclerosis and Future Cardiovascular Health Hypertension. 2010; 56: 1026-1034

[29] Taylor RN, Davidge ST, Roberts JM: Endothelial cell dysfunction and oxidative stress. In Lindheimer MD, Roberts JM,Cunningham FG(eds): Chesley's Hypertensive Disorders in Pregnany, 3rd ed. Elseveir, In press 2009.

[30] Maynard SE, Min J-Y, Merchan J, et al: Excess placental soluble fms - like tyrosine kinase 1 (Sflt) may contribute to endothelial dysfunction, hypertension and proteinuria in preeclampsia. $\mathrm{J}$ Clin Invest 111(5):649, 2003 et al

[31] Drewlo, Vesta Lai, David Z.I. Cherney and Michelle A. Hladunewich Intrauterine

Volume 5 Issue 6, June 2016 www.ijsr.net 